\title{
THE INFLUENCE OF TRANSPORT INFRASTRUCTURE DEVELOPMENT ON BIRD DIVERSITY AND ABUNDANCE
}

\author{
MARYAM RASHIDI $^{1}$, ATEFEH CHAMANI ${ }^{*}$, MINOO MOSHTAGHI
}

${ }^{1}$ Environmental Science Department, Islamic Azad University, Isfahan (Khorasgan) Branch, Isfahan, Iran; e-mail: atefehchamani@yahoo.com

${ }^{2}$ Young Researchers and Elite Club, Isfahan (Khorasgan) Branch, Islamic Azad University, Isfahan, Iran

* Author for correspondence

\begin{abstract}
Rashidi M., Chamani A., Moshtaghi M.: The influence of transport infrastructure development on bird diversity and abundance. Ekológia (Bratislava), Vol. 38, No. 2, p. 178-188, 2019.

In recent decades, detrimental effects of roads have been the focus of numerous studies. Roadways have various negative effects, such as habitat fragmentation, noise and air pollution, on bird communities. This study was aimed to investigate the effects of traffic noise on the bird's abundance during autumn period. Field operations were performed in a forest located parallel to a main high-traffic highway. The bird's abundance was recorded using a point counting method at 27 points along three transects $(65,335$ and $605 \mathrm{~m}$ from the road). The counting at each point was conducted every five minutes and repeated once every week (12 times during autumn). Environmental indices including the number of trees with DBH of over $20 \mathrm{~cm}$, the number of standing dead trees, canopy cover percentage and Leq 30 were also measured. A total of 2950 bird belonging to 30 species were observed. The number of dominant species (more than 10) in the area considerably changed as the distance from the road increased. Leq 30 had the greatest correlation coefficient with bird abundance. Therefore, traffic noise has negative effects on the bird's abundance in this area.
\end{abstract}

Key words: Leq 30, SPL, transect, traffic density.

\section{Introduction}

Diversity is the most important aspect of the community structure (Zhukov et al., 2018). The unceasing development of civilization and urbanization has changed the habitats of many animals especially birds (Wight, 2002). These changes exhibit pollution, soil destruction and plant formation, which leads to ecosystem transformation (Blinkova, Shupova, 2017). Degradation of migrating birds' habitats has decreased numerous bird species (Š́lek et al., 2010).

Natural and semi-natural forests as a buffer for urban ecosystems play a key role in reducing the negative impacts of anthropogenic impacts (Blinkova, Shupova, 2018).

In recent decades, the detrimental effects of anthropogenic noise on bird diversity have been the focus of numerous studies (Antze, Koper, 2018; Cardoso et al., 2018; Curry et al., 2018a; Kleist et al., 2018; Machado et al., 2017; Mulholland et al., 2018; Polak et al., 2013; Varasteh, 2011; Wiącek et al., 2015). Roadways have various negative effects on bird communities (Freed, Cann, 2009). 
These effects include an increase in mortality rates (Mumme et al., 2000), changing the pattern of bird distribution due to constant traffic noise (Rao, Koli, 2017) and habitat fragmentation by creating a barrier to the birds' natural movement (Gerlach, Musolf, 2000; Summers et al., 2011).

Road networks can separate animal population into subpopulations which severely constrain their genetic flow due to inbreeding (Peris, Pescador, 2004). Based on habitat type and road characteristics (Forman et al., 2002), these negative effects, may reach up to 10 or $100 \mathrm{~m}$ away from a particular habitat. Birds generally avoid habitats manipulated by human, as it has negative effects on their nutrition, survival, and abundance (Fernández-Juricic, 2002).

The annual cycle of bird migration, lasts for nearly one-third of the year (Sauer et al., 2011). During this period, birds spend considerably more time at stopover sites (Wikelski et al., 2003). Food seeking and resting may cover $95 \%$ of their migration time (Alerstam, 2003). Human activities are one of the most important factors affecting the migration of birds and the time they spend at stopover sites. The effects of noise pollution on species depend on age, gender, species history, habitat type, season, activity time and so on (Summers et al., 2011). The long-term implications of chronic noise exposure, on adult and nestling corticosterone levels, and nestling body condition has been proved (Injaian et al., 2018). Some birds in proximity to sound, have mechanisms for modulating their effects. But the usefulness of these mechanisms varies, based on physiological differences between different species (Curry et al., 2018b).

Such issues have raised major concerns about the sustainability and survival of wildlife populations near the roads (Polak et al., 2013). Therefore, this study was aimed to investigate the effects of traffic noise on the diversity and abundance of bird populations in urban ecosystems.

\section{Materials and methods}

\section{Study area}

This study, was performed in Isfahan, a city located 30-50 km from the centre of Isfahan Province covering an area of 34,500 ha $\left(32^{\circ} 30^{\prime} 20^{\prime \prime} \mathrm{N}, 51^{\circ} 30^{\prime} 15^{\prime \prime} \mathrm{E}-32^{\circ} 48^{\prime} 10^{\prime \prime} \mathrm{N}, 51^{\circ} 47^{\prime} 10^{\prime \prime} \mathrm{E}\right)$. The studied forest is located parallel to a main high-traffic highway. The dominant tree species in this area are Pinus sp., Salix sp., Acer sp., Melia azedarach, Platanus racemose, Myrtus communis, Tamarix ramosissima and Elaeagnus sp. During the study period, the average traffic intensity was 1106 personal vehicles, 53 heavy vehicles, and 92 motorcycles per hour. The speed limit in this highway is $60 \mathrm{~km} / \mathrm{h}$.

\section{The number and distances of transects}

Three transects (respectively 65, 335, and $605 \mathrm{~m}$ from the road) were selected considering the forest area. The transverse and longitudinal distances of the transects were 270 and $150 \mathrm{~m}$, respectively. Nine points in each transect, with $75 \mathrm{~m}$ distances, were determined along each transect (A total of 27 points). The bird's abundance along each transect were estimated every 5 minutes using the point count method. Based on the transverse and longitudinal distances of the transects also the tree cover density and visibility, all birds were recorded within a $50 \mathrm{~m}$ radius (West et al., 2002; Wiącek et al., 2015).

Numbers of birds

The birds were observed and identified using a binocular. The observations began in autumn 2016, under favourable weather conditions. That is, in the absence of rainfall or extreme wind blows. The counting started at sunrise, when birds had maximum activity and were most likely to be seen, and continued until 2 p.m. (Mammides et al., 2017). In order to estimate the species' abundance, the numbers of species identified in the three transects were counted and recorded. Counting at each point was done once every week (12 times during autumn). All observations were made by two expert observers. All the birds were identified with the help of the Iranian bird guides. To eliminate possible errors in the observa- 
tion hours, observations were conducted in a different order as described by (Wiącek et al., 2015). Each day, the observation began from the point it had ended the day before. In addition, since birds with different diets have different ecological niches, the birds were categorized into three: granivorous, insectivores, and omnivores (Polak et al., 2013).

\section{Environmental parameters}

The environmental indices, including the number of trees with a diameter at breast height (DBH) of over $20 \mathrm{~cm}$, number of dead trees (NDT), canopy cover percentage and temperature, were measured in all transects. In order to calculate the trees' DBH, the diameter of each tree was measured at breast height $(1.3 \mathrm{~m})$ and the DBH was obtained using the circle circumference formula. In order to determine the canopy cover percentage, a measuring tape was used to measure the radius of each tree's shadow in favourable, sunny conditions when the tree shadows could be distinguished. The area of the shadows was then calculated and divided by the area of each transect. Finally, the temperature data were collected from the weather station in the area.

\section{Sound measurement}

The equivalent sound level (Leq30) represents the estimated sound average over a period of $30 \mathrm{~min}$. Leq30 was used in this study because least error was detected during the measurement of equivalent sound level (Wang et al., 2005). Leq30 was measured at the central station of each transect for over a 5-15-min period using a sound level meter model TES 1353. To minimize the effects of ground vibration factors, the measurements were performed a the height of 1-2 $\mathrm{m}$ above the ground (Machado et al., 2017). The sound pressure level (SPL), minimum, maximum, and average sound level (as the most important factor used), and Leq30 were also estimated during this interval. Vehicle traffic rates were also camera recorded and calculated throughout the sound measurement period. To determine day(s) with higher noise pollution (peak days), the traffic rates were measured daily during the week. The traffic rate was measured by direct observation and recorded with hand camera. Traffic vehicles were then divided into three different classes including trucks, cars, and motorcycles.

\section{Statistical analysis}

The homogeneity and normal distribution of data were analysed using SPSS 23.0 (SPSS Inc., Chicago, IL, USA). DISTANCE 6.0 was used to calculate the bird density. The relationship between the bird abundance and environmental variables were investigated using CANOCO. Other statistical analyses (ANOVA, ANCOVA, PCA, correlation coefficients and so on), were conducted using STATISTICA 10.0 .

\section{Results and discussion}

A total of 2950 bird belonging to 30 species were observed in the study area (Table 1). The most dominant order was Passeriformes. The least abundance belonged to Piciformes, Coraciiformes, and Psittaciformes. All the observed species was in the Least Concern category (IUCN). The environmental indices in the area are shown in Table 2. According to the Shapiro-Wilk test, data from the three transects had normal distribution $(\mathrm{P}=0.205,0.174$, and 0.579 for transects $1-3$, respectively) and were analysed using the parametric tests. Moreover, Levene's test confirmed the homogeneity of the data $\left(\mathrm{F}_{1}=2, \mathrm{~F}_{2}=15 ; \mathrm{P}=0.132\right)$. One-way ANOVA and Duncan's test $(\mathrm{F}=36.24 ; \mathrm{P}<0.05)$ showed a significant difference in the mean species presence among the three transects.

Figure 1 shows significantly increasing species richness with distances from the road. The number of dominant species $(>10)$ in the region considerably changed with distance from the road. The abundance of Columba palumbus, Psittacula krameri, Corvus frugilegus and C. corone increased with distance from the road. While some species, such as Motacilla alba, Spilopelia senegalensis and Motacilla flava, preferred the middle transect. 


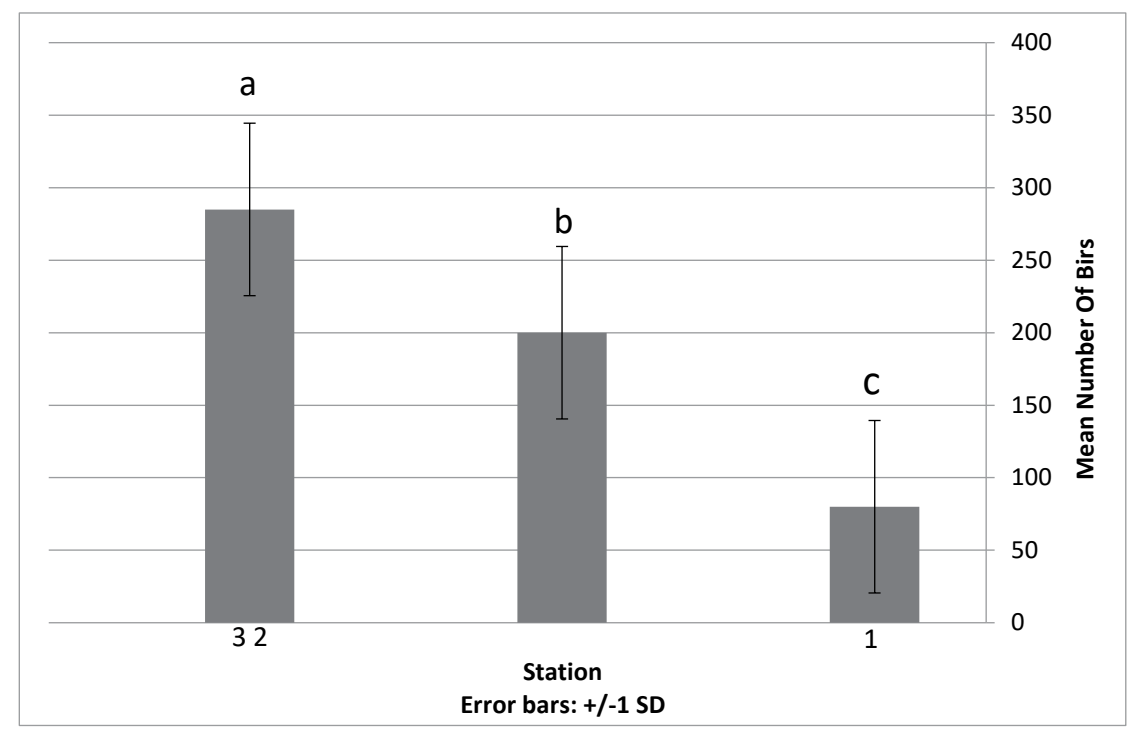

Fig. 1. The mean and standard deviation of bird abundance in transects 1-3 (different letters, indicate significant differences at the 0.05 level).

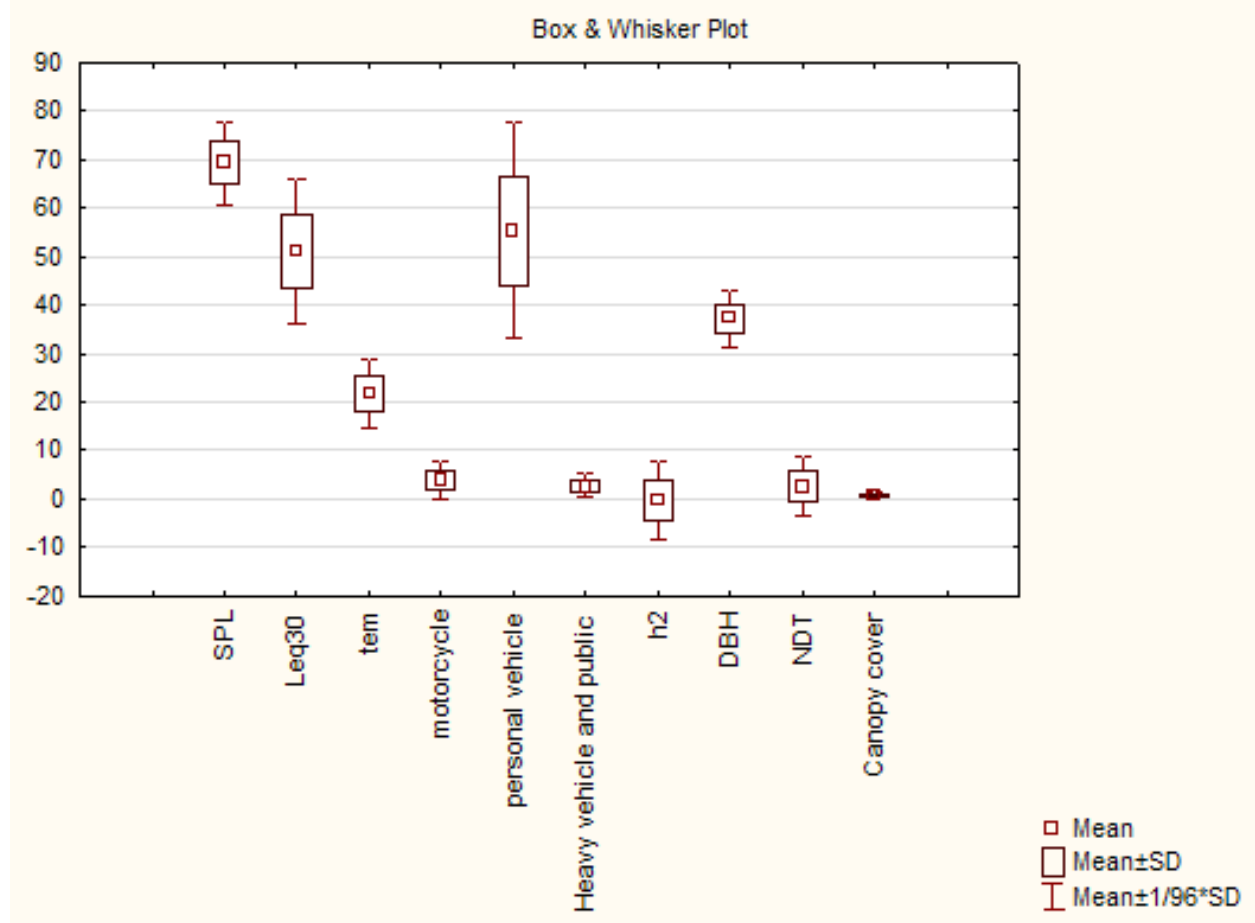

Fig. 2. Box \& Whisker Plot. 
T a b l e 1 . The observed and identified species in study area.

\begin{tabular}{|c|c|c|c|c|c|}
\hline \multirow{2}{*}{ Species } & \multirow{2}{*}{ Total number } & \multirow{2}{*}{ Foraging guild } & \multicolumn{3}{|c|}{ Number of individuals } \\
\hline & & & T1 & T2 & T3 \\
\hline Corvus corone & 400 & $\mathrm{O}$ & 75 & 107 & 218 \\
\hline Pica pica & 192 & $\mathrm{O}$ & 59 & 66 & 67 \\
\hline Motacilla alba & 570 & G & 132 & 249 & 189 \\
\hline Corvus florensis & 791 & $\mathrm{O}$ & 38 & 144 & 609 \\
\hline Passer domesticus & 648 & G & 105 & 292 & 254 \\
\hline Phylloscopus collybita & 47 & $\mathrm{I}$ & 3 & 21 & 48 \\
\hline Accipiter nisus & 1 & - & 1 & 0 & 0 \\
\hline Tringa solitaria & 314 & - & 0 & 277 & 37 \\
\hline Actitis hypoleucos & 2 & I & 0 & 1 & 1 \\
\hline Tringa totanus & 2 & - & 0 & 1 & 1 \\
\hline Spilopelia senegalensis & 21 & G & 2 & 12 & 7 \\
\hline Gallinago gallinago & 21 & $\mathrm{I}$ & 0 & 12 & 9 \\
\hline Pyrrhocorax pyrrhocorax & 1 & $\mathrm{O}$ & 0 & 0 & 1 \\
\hline Motacilla cinerea & 3 & G & 0 & 0 & 3 \\
\hline Acrocephalus arundinaceus & 4 & I & 0 & 0 & 4 \\
\hline Sylvia atricapilla & 4 & I & 0 & 0 & 4 \\
\hline Dendrocopos syriacus & 11 & G & 5 & 3 & 3 \\
\hline Accipiter brevipes & 2 & - & 0 & 0 & 2 \\
\hline Egretta garzetta & 12 & I & 0 & 0 & 12 \\
\hline Hippolais caligata & 14 & I & 8 & 2 & 4 \\
\hline Circus pygargus & 1 & $\mathrm{I}$ & 0 & 0 & 1 \\
\hline Galerida cristata & 27 & G & 2 & 10 & 15 \\
\hline Gallinula chloropus & 45 & G & 0 & 22 & 23 \\
\hline Hippolais languida & 10 & I & 0 & 7 & 3 \\
\hline Upupa epops & 1 & I & 0 & 1 & 0 \\
\hline Psittacula krameri & 14 & G & 0 & 2 & 12 \\
\hline Columba livia & 12 & G & 6 & 6 & 0 \\
\hline Columba palumbus & 109 & G & 8 & 5 & 96 \\
\hline Motacilla citreola & 3 & G & 0 & 1 & 2 \\
\hline Motacilla flava feldegg & 10 & G & 0 & 10 & 0 \\
\hline Acridotheres tristis & 9 & $\mathrm{O}$ & 0 & 0 & 9 \\
\hline Falco tinnunculus & 1 & - & 0 & 0 & 1 \\
\hline Fringilla coelebs & 2 & G & 0 & 2 & 0 \\
\hline Anthus campestris & 1 & $\mathrm{I}$ & 0 & 1 & 0 \\
\hline Anas platyrhynchos & 5 & $\mathrm{O}$ & 0 & 5 & 0 \\
\hline Luscinia svecica & 1 & $\mathrm{I}$ & 0 & 0 & 1 \\
\hline Larus ridibundus & 17 & G & 0 & 0 & 17 \\
\hline Lanius collurio & 1 & $\mathrm{I}$ & 0 & 0 & 1 \\
\hline Total & 3329 & & 444 & 1249 & 1618 \\
\hline
\end{tabular}


T a b l e 2. Environmental indices in the area.

\begin{tabular}{|l|c|c|c|}
\hline Variable & T1 & T2 & T3 \\
\hline SPL & 75.5 & 68.1 & 65.1 \\
\hline Leq30 & 60.7 & 46.8 & 45.3 \\
\hline Motorcycle & 23 & 0 & 0 \\
\hline Personal vehicle & 55.3 & 0 & 0 \\
\hline Heavy vehicle and public & 2.6 & 0 & 0 \\
\hline DBH & $25 / 62$ & 33.22 & 7.8 \\
\hline NDT & 11 & 2 & 2 \\
\hline Canopy cover & $0 / 78$ & $0 / 44$ & $1 / 18$ \\
\hline $\mathbf{H}$ & 1587.333 & 1582.333 & 1582 \\
\hline $\mathbf{\Delta h}$ & $\mathbf{- 5}$ & $\mathbf{- 0 . 3 3 3}$ & $\mathbf{5 . 3 3 3 3 3 3}$ \\
\hline
\end{tabular}

Figure 2 shows the mean and standard deviation of the environmental variables. Accordingly, the sound parameters are in the same range with the vehicle traffic and environmental parameters.

As shown in Figs 3 and 4, SPL and Leq30 was significantly decreased with distance from the road. While Leq30 in transect 1 had significant differences with transects 2 and 3 , no other significant differences in Leq30 were observed.

As shown in Figure 5, four Principal Components (PCs) explained 65.4\% of the total variation. Of this total, $18.9 \%$ was explained by PC1 in which Leq30, NDT, DBH, distance from the road and heavy vehicle were mainly responsible for this variation; $18.4 \%$ can be explained by PC2 which is mainly attributed to SPL and personal vehicle; $10.6 \%$ was explained by PC3 can mainly be attributed to temperature, motorcycle and h; and 5\% was explained by PC4 in which canopy cover was more important.

Since regression models (Table 3) are used to prioritize the effect size of variables, they can be used to clarify the most important factors involved in the presence of specific species by calculating the differences between the R values. Moreover, the mean square (MS) can determine the effects of factors on each other.

According to the results, Leq30 had the highest correlation coefficient with species richness. Therefore, traffic noise had negative effects on the bird abundance and diversity in this area. Specifically, motorcycles were found to produce evasive sounds beyond the normal levels and ensure the absence of bird species.

\section{Discussion}

Biodiversity indices facilitate the identification of factors affecting habitats and serve as a tool for monitoring and evaluation of changes in ecosystem (Ramp et al., 2005). Based on the PCA results, DBH, NDT, Leq30, and distance from the road had the greatest impacts on the abundance and diversity of bird species. Similarly, (McClure et al., 2013) found decreased abundance and diversity of species in areas adjacent to roads. In the present study, the lowest abundance was observed in the first transect located nearest to the road with maximum levels of traffic noise. The presence of 


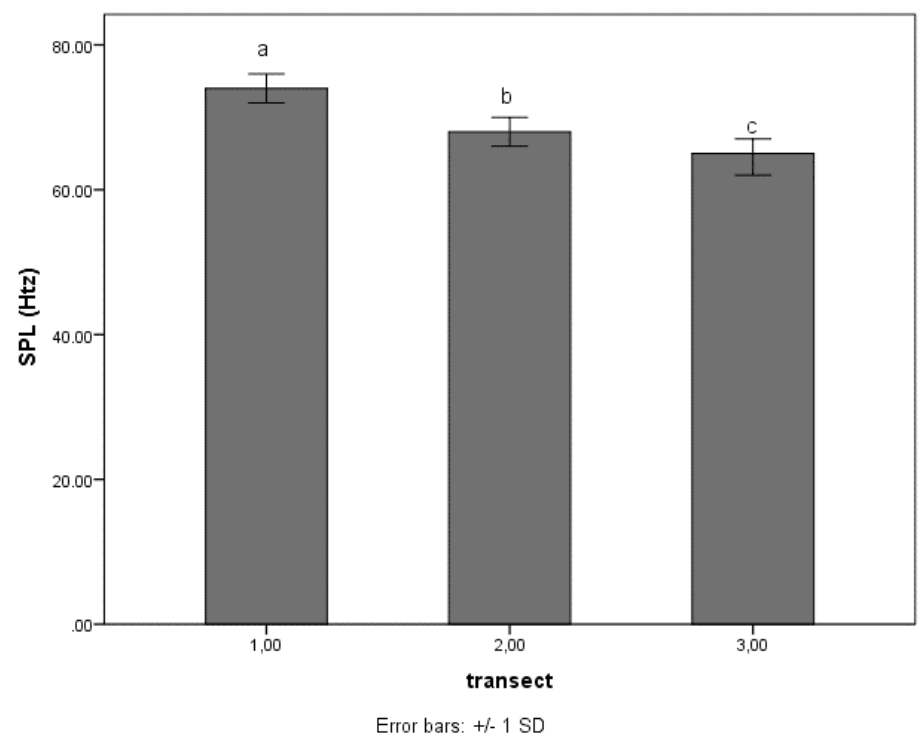

Fig. 3. The mean and standard deviation of SPL in transects 1-3 (different letters, indicate significant differences at the 0.05 level).

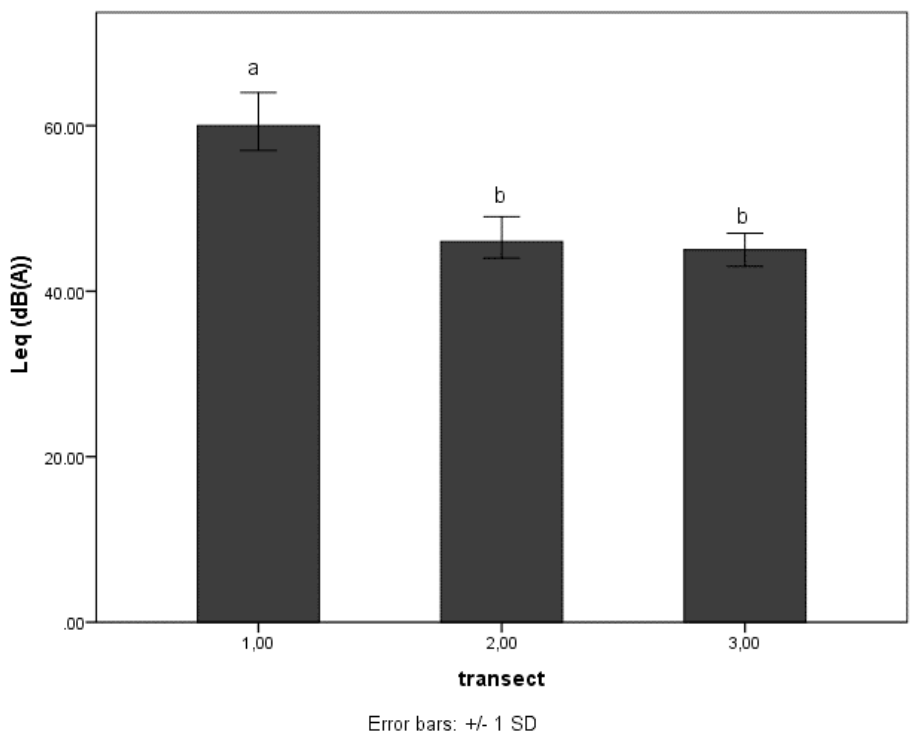

Fig. 4. The mean and standard deviation of $\mathrm{Leq}_{30}$ in transects 1-3 (different letters, indicate significant differences at the 0.05 level).

most species increased with the distance from the road as a result of greater security and silence in the second and third transects. Thus, as reported by Polak et al. (2013), roads act as a limiting factor for the presence of species. 
Based on the results, motor vehicle traffic rates had direct correlations with Leq30 and SPL. Personal vehicles had the greatest impacts and motor vehicles had the least significant effects on SPL. In other words, higher traffic was associated with greater levels of sound equivalent and pressure. Moreover, Leq30 had the highest correlation with the diversity of species. Therefore, the noise pollution caused by traffic negatively affected the bird species' diversity and abundance in the region.

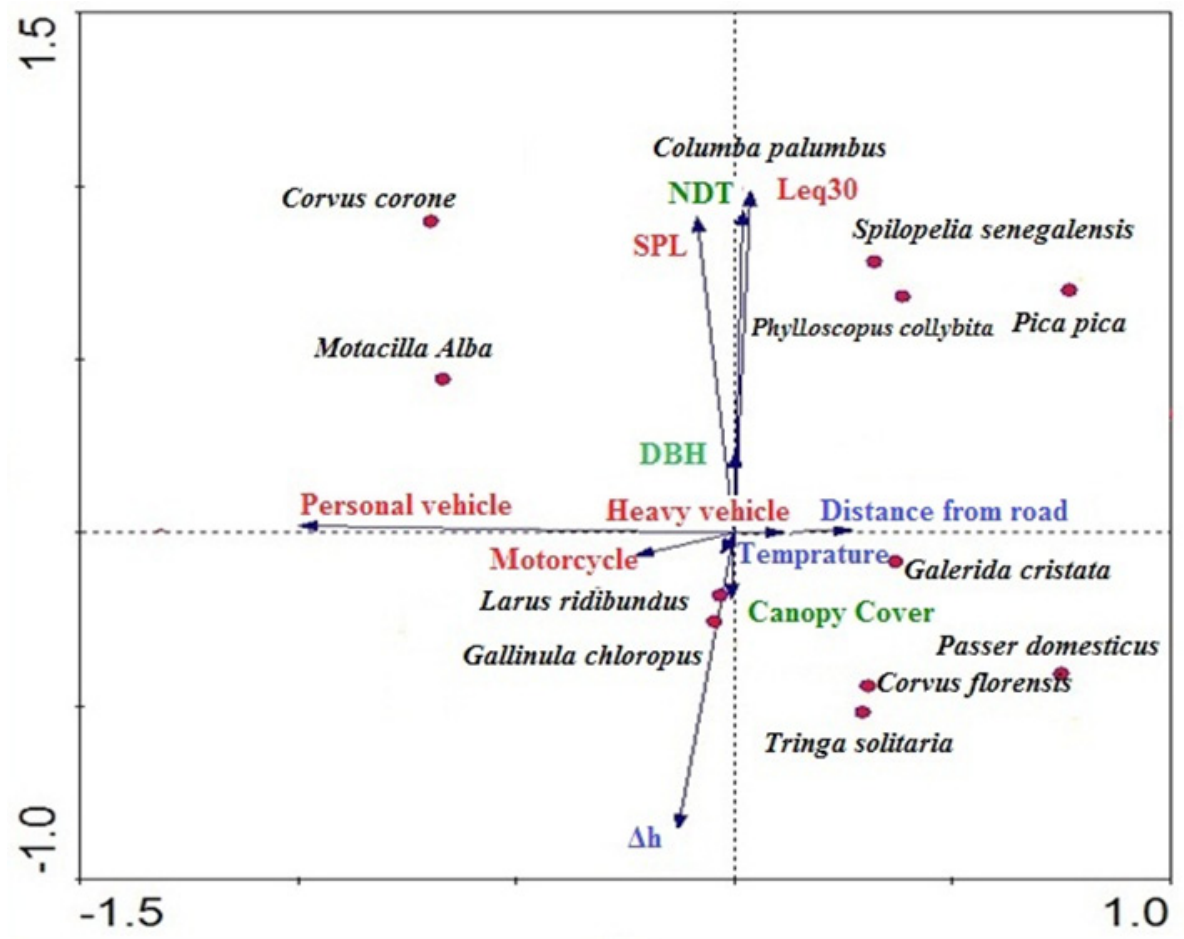

Fig. 5. Ordination diagram of PCA with 12 of the highest bird species richness.

Among the vegetation factors, NDT was the most effective parameter (correlation=1) in increasing the abundance of species, such as Pica pica and Corvus corone, which nested on dead trees. Noise pollution and vehicle traffic rates did not play significant roles in the presence of these species. This highlighted the importance of NDT and the need for the preservation of dead trees in the habitats of the mentioned species (Sillett, Holmes, 2002). Sillett and Holmes (2002), in their study, identified the preservation of at least six dead trees per hectare (one with a diameter $\geq 50$ $\mathrm{cm}$ and others with a diameter $\geq 40 \mathrm{~cm}$ ) as a valuable management strategy. 
T a b l e 3. Modelling the regression correlation coefficients between sound-dependent environmental factors.

\begin{tabular}{|c|c|c|c|c|c|c|c|c|c|c|c|}
\hline $\begin{array}{l}\text { Dependent } \\
\text { Variable }\end{array}$ & 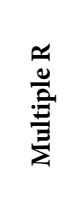 & $\frac{\widetilde{\pi}}{\frac{\pi}{2}}$ & 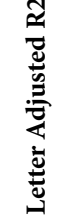 & $\begin{array}{l}\bar{\Xi} \\
\sum_{0}^{0} \\
\dot{s}\end{array}$ & 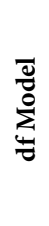 & 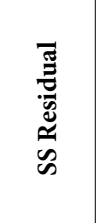 & 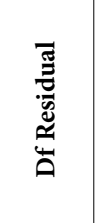 & 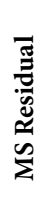 & 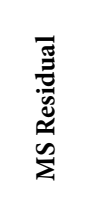 & 山 & a \\
\hline SPL & 0.44 & 0.2 & 0.15 & 0.68 & 1 & 68.05 & 269.55 & 16 & 16.84 & 4.03 & 0.06 \\
\hline Leq 30 & 0.61 & 0.3 & 0.34 & 375.38 & 1 & 375.38 & 613.21 & 16 & 38.32 & 9.79 & 0.006 \\
\hline temp & 0.076 & 0.005 & -0.05 & 1.3 & 1 & 1.33 & 223.83 & 16 & 13.98 & 0.09 & 0.76 \\
\hline motorcycle & 0.51 & 0.26 & 0.22 & 20.05 & 1 & 20.05 & 55.44 & 16 & 3.4 & 5.89 & 0.02 \\
\hline $\begin{array}{l}\text { Personal } \\
\text { vehicle }\end{array}$ & 0.43 & 0.18 & 0.13 & 410.88 & 1 & 410.88 & 178.31 & 16 & 111.44 & 3.68 & 0.07 \\
\hline $\begin{array}{l}\text { Heavy vehicle } \\
\text { and public }\end{array}$ & 0.35 & 0.12 & 0.07 & 3.55 & 1 & 3.55 & 24.44 & 16 & 1.52 & 2.32 & 0.14 \\
\hline
\end{tabular}

Shelter is a major biological need for most birds. This need was clearly detected in the case of Psittacula krameri, whose presence was mostly observed in the third transect near the willow community. The presence of Salix sp. in the second and third transects can be a very good shelter for birds to create different ecological niches. The presence of Motacilla flava was observed in the second transect where Tamarix ramosissima existed. The presence of Acridotheres tristis was observed in the third transect owing to the existence of Populus euphratica and Platanus sp. Higher percentage of vegetation canopy increased the abundance of species, such as Phylloscopus collybita and Dendrocopos syriacus for which canopy is a key factor in habitat selection. Shade-friendly bird species, such as Motacilla alba, would be forced to change their distribution range to areas near roads where canopy cover is higher than the average level ( 0.78 vs. $14.4 \%)$ due to the presence of planted species. This can provide a safe shelter for vulnerable species, such as M. alba. Hence, some species prioritize shelter over other habitat parameters. Furthermore, canopy cover is more effective than traffic rate and noise pollution in their habitat selection. According to other studies, depending on the species, roads can either decrease (Forman et al., 2002) or increase the diversity of birds (Meunier et al., 1999).

Furthermore, changes in elevation in an ecosystem can also justify altered birds' fauna in the studied transects. Since the average temperature was constant during the study period, it did not directly affect the presence or absence of species. $\mathrm{DBH}$ and tree height are also other important variables in the habitat structure and can be individually used in other investigations due to homogeneity of variances. (Díaz, 2006) emphasized the positive relationships between habitat parameters and species diversity and abundance (Morelli et al., 2014) concluded that changes in the habitat flora was associated with changes in birds' fauna and that the presence of species was limited by the specific habitat conditions in each area. Increasing the area, safety and diversity of aquatic plants play important roles in attracting more aquatic and offshore birds (Fox, Bell, 1994). Cavity-nesting birds, which are dependent upon dead 
trees with specific diameter, height, and degrees of corruption, are the most vulnerable to the marginal effects of roads. Elimination of these parameters will increase the vulnerability of primary cavity-nesting birds, such as woodpeckers (Kilgo, 2005).

The results of this study can effectively help in the planning, management, and development of road construction in forest areas where the protection of bird species from noise pollution is intended.

\section{References}

Alerstam, T. (2003). Bird migration speed. In P. Berthold, E. Guinner \& E. Sonnenschein (Eds.), Avian migration (pp. 253-267). Berlin, Heidelberg: Springer. DOI: 10.1007/978-3-662-05957-9_17.

Antze, B. \& Koper N. (2018). Noisy anthropogenic infrastructure interferes with alarm responses in Savannah sparrows (Passerculus sandwichensis). Royal Society Open Science, 5(5), 172168. DOI: 10.1098/rsos.172168.

Blinkova, O. \& Shupova T. (2017). Bird communities and vegetation composition in the urban forest ecosystem: correlations and comparisons of diversity indices. Ekológia (Bratislava), 36(4), 366-387. DOI: 10.1515/eko-2017-0029.

Blinkova, O. \& Shupova T. (2018). Bird communities and vegetation composition in natural and semi-natural forests of megalopolis: correlations and comparisons of diversity indices (Kyiv city, Ukraine). Ekológia (Bratislava), 37(3), 259-288. DOI: 10.2478/eko-2018-0021.

Cardoso, G.C., Hu, Y. \& Francis C.D. (2018). The comparative evidence for urban species sorting by anthropogenic noise. Royal Society Open Science, 5(2), 172059. DOI: 10.1098/rsos.172059.

Curry, C.M., Antze, B., Warrington, M.H., Des Brisay, P., Rosa, P. \& Koper N. (2018a). Ability to alter song in two grassland songbirds exposed to simulated anthropogenic noise is not related to pre-existing variability. Bioacoustics, 27(2), 105-130.

Curry, C.M., Des Brisay, P.G., Rosa, P. \& Koper N. (2018b). Noise source and individual physiology mediate effectiveness of bird songs adjusted to anthropogenic noise. Scientific Reports, 8(1), 3942. DOI: 10.1038/s41598018-22253-5.

Díaz, L. (2006). Influences of forest type and forest structure on bird communities in oak and pine woodlands in Spain. For. Ecol. Manag., 223(1-3), 54-65. DOI: 10.1016/j.foreco.2005.10.061.

Fernández-Juricic, E. (2002). Can human disturbance promote nestedness? A case study with breeding birds in urban habitat fragments. Oecologia, 131(2), 269-278. DOI: 10.1007/s00442-002-0883-y.

Forman, R.T., Reineking, B. \& Hersperger A.M. (2002). Road traffic and nearby grassland bird patterns in a suburbanizing landscape. Environ. Manag., 29(6), 782-800. DOI: 10.1007/s00267-001-0065-4.

Fox, A. \& Bell M. (1994). Breeding bird communities and environmental variable correlates of Scottish peatland wetlands. In J.J. Kerekes (Ed.), Aquatic birds in the trophic web of lakes (pp. 297-307). Dordrecht: Springer. DOI: 10.1007/978-94-011-1128-7.

Freed, L.A. \& Cann R.L. (2009). Negative effects of an introduced bird species on growth and survival in a native bird community. Curr. Biol., 19(20), 1736-1740. DOI: 10.1016/j.cub.2009.08.044.

Gerlach, G. \& Musolf K. (2000). Fragmentation of landscape as a cause for genetic subdivision in bank voles. Conserv. Biol., 14(4), 1066-1074. DOI: 10.1046/j.1523-1739.2000.98519.x.

Injaian, A.S., Taff, C.C., Pearson, K.L., Gin, M.M.Y., Patricelli, G.L. \& Vitousek M.N. (2018). Effects of experimental chronic traffic noise exposure on adult and nestling corticosterone levels, and nestling body condition in a freeliving bird. Hormones and Behavior, 106, 19-27. DOI: 10.1016/j.yhbeh.2018.07.012.

Kilgo, J.C. (2005). Harvest-related edge effects on prey availability and foraging of Hooded Warblers in a bottomland hardwood forest. The Condor, 107(3), 627-636. DOI: 10.1650/0010-5422(2005)107[0627:HEEOPA]2.0.CO;2.

Kleist, N.J., Guralnick, R.P., Cruz, A., Lowry, C.A. \& Francis C.D. (2018). Chronic anthropogenic noise disrupts glucocorticoid signaling and has multiple effects on fitness in an avian community. Proc. Nat. Acad. Sci. USA, 115(4), E648-E657. DOI: 10.1073/pnas.1709200115.

Machado, R. B., Aguiar, L. \& Jones G. (2017). Do acoustic indices reflect the characteristics of bird communities in the savannas of Central Brazil? Landsc. Urban Plann., 162, 36-43. DOI: 10.1016/j.landurbplan.2017.01.014.

Mammides, C., Goodale, E., Dayananda, S.K., Kang, L. \& Chen J. (2017). Do acoustic indices correlate with bird diversity? Insights from two biodiverse regions in Yunnan Province, south China. Ecological Indicators, 82, 470-477. DOI: 10.1016/j.ecolind.2017.07.017. 
Mcclure, C.J., Ware, H.E., Carlisle, J., Kaltenecker, G. \& Barber J.R. (2013). An experimental investigation into the effects of traffic noise on distributions of birds: avoiding the phantom road. Proc. R. Soc. Lond. B: Biol. Sci., 280(1773), 1-9. DOI: 10.1098/rspb.2013.2290.

Meunier, F.D., Verheyden, C. \& Jouventin P. (1999). Bird communities of highway verges: influence of adjacent habitat and roadside management. Acta Oecol., 20(1), 1-13. DOI: 10.1016/S1146-609X(99)80010-1.

Morelli, F., Beim, M., Jerzak, L., Jones, D. \& Tryjanowski P. (2014). Can roads, railways and related structures have positive effects on birds?-A review. Transportation Research Part D: Transport and Environment, 30, 21-31. DOI: 10.1016/j.trd.2014.05.006.

Mulholland, T.I., Ferraro, D.M., Boland, K.C., Ivey, K.N., Le, M.-L., Lariccia, C.A., Vigianelli, J.M. \& Francis C.D. (2018). Effects of experimental anthropogenic noise exposure on the reproductive success of secondary cavity nesting birds. Integrative and Comparative Biology, 58(5), 967-976. DOI: 10.1093/icb/icy079.

Mumme, R.L., Schoech, S.J., Woolfenden, G.E. \& Fitzpatrick J.W. (2000). Life and death in the fast lane: Demographic consequences of road mortality in the Florida Scrub-Jay. Conserv. Biol., 14(2), 501-512. DOI: 10.1046/j.15231739.2000.98370.x.

Peris, S. \& Pescador M. (2004). Effects of traffic noise on paserine populations in Mediterranean wooded pastures. Applied Acoustics, 65(4), 357-366. DOI: 10.1016/j.apacoust.2003.10.005.

Polak, M., Wiącek, J., Kucharczyk, M. \& Orzechowski R. (2013). The effect of road traffic on a breeding community of woodland birds. European Journal of Forest Research, 132(5-6), 931-941. DOI: 10.1007/s10342-013-0732-z.

Ramp, D., Caldwell, J., Edwards, K.A., Warton, D. \& Croft D.B. (2005). Modelling of wildlife fatality hotspots along the snowy mountain highway in New South Wales, Australia. Biol. Conserv., 126(4), 474-490. DOI: 10.1016/j. biocon.2005.07.001.

Rao, S. \& Koli V.K. (2017). Edge effect of busy high traffic roads on the nest site selection of birds inside the city area: Guild response. Transportation Research Part D: Transport and Environment, 1, 94-101. DOI: 10.1016/j. $\operatorname{trd}$.2016.12.013.

Sauer, J., Hines, J., Fallon, J., Pardieck, K., Ziolkowski Jr, D. \& Link W. (2011). The North American Breeding Bird Survey Results and Analysis 1966-2009. Version 3.23. 2011 (USGS Patuxent Wildlife Research Center, Laurel, MD). Accessed Dec.

Sillett, T.S. \& Holmes R.T. (2002). Variation in survivorship of a migratory songbird throughout its annual cycle. J. Anim. Ecol., 71(2), 296-308. DOI: 10.1046/j.1365-2656.2002.00599.

Summers, P.D., Cunnington, G.M. \& Fahrig L. (2011). Are the negative effects of roads on breeding birds caused by traffic noise? J. Appl. Ecol., 48(6), 1527-1534. DOI: 10.1111/j.1365-2664.2011.02041.x.

Šálek, M., Svobodová, J. \& Zasadil P. (2010). Edge effect of low-traffic forest roads on bird communities in secondary production forests in central Europe. Landsc. Ecol., 25(7), 1113-1124. DOI: 10.1007/s10980-010-9487-9.

Varasteh, M.H. (2011). Assessing the impacts of tehran-mashhad asian highway on bird community in Golestan national park. Environmental Research, 2(30), 21-34.

Wang, L.K., Pereira, N.C. \& Hung Y.-T. (2005). Advanced air and noise pollution control. Springer.

West, A.D., Goss-Custard, J.D., Stillman, R.A., Caldow, R.W., Dit Durell, S.E.L.V. \& Mcgrorty S. (2002). Predicting the impacts of disturbance on shorebird mortality using a behaviour-based model. Biol. Conserv., 106(3), 319-328. DOI: 10.1016/S0006-3207(01)00257-9.

Wiącek, J., Polak, M., Kucharczyk, M. \& Bohatkiewicz J. (2015). The influence of road traffic on birds during autumn period: implications for planning and management of road network. Landsc. Urban Plann., 134, 76-82. DOI: 10.1016/j.landurbplan.2014.10.016.

Wight, P.A. (2002). Supporting the principles of sustainable development in tourism and ecotourism: government's potential role. Current Issues in Tourism, 5(3-4), 222-244. DOI: 10.1080/13683500208667920.

Wikelski, M., Tarlow, E. M., Raim, A., Diehl, R. H., Larkin, R. P. \& Visser G. H. (2003). Avian metabolism: costs of migration in free-flying songbirds. Nature, 423 (6941), 704. DOI: 10.1038/423704a.

Zhukov, O., Kunah, O., Dubinina, Y. \& Novikova V. (2018). The role of edaphic and vegetation factors in structuring beta diversity of the soil macrofauna community of the Dnipro river arena terrace. Ekológia (Bratislava), 37(4), 301-327. DOI: 10.2478/eko-2018-0023. 